\section{(2) OPEN ACCESS}

\title{
Maintenance of clinical remission in early axial spondyloarthritis following certolizumab pegol dose reduction
}

\author{
Robert BM Landewé, ${ }^{1,2}$ Désirée van der Heijde (D) , ${ }^{3}$ Maxime Dougados, ${ }^{4}$ \\ Xenofon Baraliakos, ${ }^{5}$ Filip E Van den Bosch, ${ }^{6}$ Karl Gaffney, ${ }_{1}^{7}$ Lars Bauer, ${ }^{8}$ \\ Bengt Hoepken, ${ }^{8}$ Owen R Davies, ${ }^{9}$ Natasha de Peyrecave, ${ }^{10}$ Karen Thomas, $^{8}$ \\ Lianne Gensler ${ }^{11}$
}

Handling editor Josef $S$ Smolen

- Additional material is published online only. To view please visit the journal online (http://dx.doi.org/10.1136/ annrheumdis-2019-216839).

For numbered affiliations see end of article.

Correspondence to Professor Robert BM Landewé, Amsterdam Rheumatology Center, AMC, Amsterdam, The Netherlands;

landewe@rlandewe.nl

Received 16 December 2019 Revised 9 April 2020 Accepted 13 April 2020 Published Online First 7 May 2020

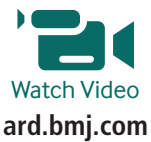

Check for updates

(C) Author(s) (or their employer(s)) 2020. Re-use permitted under CC BY-NC. No commercial re-use. See rights and permissions. Published by BMJ.

To cite: Landewé RBM, van der Heijde D, Dougados M, et al. Ann Rheum Dis

2020;79:920-928.

\section{ABSTRACT}

Background The best strategy for maintaining clinical remission in patients with axial spondyloarthritis (axSpA) has not been defined. C-OPTIMISE compared dose continuation, reduction and withdrawal of the tumour necrosis factor inhibitor certolizumab pegol (CZP) following achievement of sustained remission in patients with early axSpA.

Methods C-OPTIMISE was a two-part, multicentre phase $3 b$ study in adults with early active axSpA (radiographic or non-radiographic). During the 48-week open-label induction period, patients received CZP 200 mg every 2 weeks (Q2W). At Week 48, patients in sustained remission (Ankylosing Spondylitis Disease Activity Score (ASDAS) <1.3 at Weeks 32/36 and 48) were randomised to double-blind CZP $200 \mathrm{mg}$ Q2W (full maintenance dose), CZP 200 mg every 4 weeks (Q4W; reduced maintenance dose) or placebo (withdrawal) for a further 48 weeks. The primary endpoint was remaining flare-free (flare: ASDAS $\geq 2.1$ at two consecutive visits or ASDAS $>3.5$ at any time point) during the double-blind period.

Results At Week 48, 43.9\% (323/736) patients achieved sustained remission, of whom 313 were randomised to CZP full maintenance dose, CZP reduced maintenance dose or placebo. During Weeks 48 to 96 , $83.7 \%$ (87/104), 79.0\% (83/105) and 20.2\% (21/104) of patients receiving the full maintenance dose, reduced maintenance dose or placebo, respectively, were flarefree ( $p<0.001$ vs placebo in both CZP groups). Responses in radiographic and non-radiographic axSpA patients were comparable.

Conclusions Patients with early axSpA who achieve sustained remission at 48 weeks can reduce their CZP maintenance dose; however, treatment should not be completely discontinued due to the high risk of flare following CZP withdrawal.

Trial registration number NCT02505542,

ClinicalTrials.gov.

\section{INTRODUCTION}

Axial spondyloarthritis (axSpA) is a chronic inflammatory rheumatic disease that affects the spine and sacroiliac joints, causing pain, stiffness and fatigue. ${ }^{1-3}$ It usually manifests in early adulthood, ${ }^{4}$ and encompasses patients with radiographic sacroiliitis (radiographic axSpA) and those without

\section{Key messages}

What is already known about this subject?

- Tumour necrosis factor inhibitors (TNFi) are effective for the management of axial spondyloarthritis (axSpA), including radiographic and non-radiographic axSpA, with many patients able to achieve a state of low disease activity and remission.

- Previous studies exploring remission inductionand-maintenance strategies have shown that discontinuing TNFi after achieving remission can lead to flares in the majority of patients. However, few studies have assessed remission maintenance in a broad axSpA population, and none have formally tested a dose reduction strategy in axSpA.

\section{What does this study add?}

- C-OPTIMISE is the first randomised controlled trial to compare both TNFi dose continuation and dose reduction with the effects of treatment withdrawal in patients with axSpA who achieved sustained clinical remission after 48 weeks' open-label certolizumab pegol (CZP) treatment.

- During the randomised period of the study, significantly higher proportions of patients who continued on either a full or reduced CZP maintenance dose remained flare-free $(83.7 \%$ and $79.0 \%$, respectively) than patients who had CZP treatment withdrawn (20.2\%).

\section{How might this impact on clinical practice or future developments? \\ - CZP maintenance dose reduction is a feasible option for the long-term management of patients with axSpA in remission, preserving the clinical benefits of remaining on TNFi treatment, reducing costs and limiting patients' long-term exposure to immunosuppressive therapy.}

(non-radiographic axSpA). Symptoms cause considerable impairment to patients' physical function, work productivity and quality of life. ${ }^{56}$

Achievement of a state of low disease activity or remission is key to optimising health-related 
quality of life in patients with axSpA, and in many patients this can be reached through treatment with tumour necrosis factor inhibitors (TNFi). The high costs of $\mathrm{TNFi}^{7}$ and the possible consequences of long-term immunosuppression have raised the question of how remission, once achieved, should best be maintained. Trials in different systemic autoimmune diseases have explored remission induction-and-maintenance strategies. ${ }^{8-10}$ Such strategies have not been formally tested in patients with axSpA, although previous studies have suggested that complete treatment withdrawal often leads to relapse. ${ }^{11} 12$ Therefore, a key question remaining for clinicians is whether to maintain or reduce TNFi treatment in patients in whom sustained remission has been induced.

The PEGylated, Fc-free TNFi certolizumab pegol (CZP) is an effective and well tolerated treatment across the axSpA spectrum. ${ }^{1314}$ C-OPTIMISE is the first phase $3 \mathrm{~b}$ randomised treatment strategy trial that evaluated TNFi dose reduction in patients with early axSpA in whom sustained remission had been induced. The study included a 48-week open-label induction period, followed by a 48 -week randomised, double-blind maintenance period evaluating maintenance of remission following CZP dose continuation, CZP dose reduction or complete withdrawal.

\section{METHODS}

\section{Study design}

C-OPTIMISE was a two-part, phase $3 \mathrm{~b}$ multicentre study evaluating maintenance of remission in adult patients with early active axSpA. Patients were enrolled into the study from 108 study sites between 31 July 2015 and 24 March 2017.

During the induction period (baseline to Week 48) patients received open-label CZP $200 \mathrm{mg}$ every 2 weeks (Q2W; after a loading dose of CZP $400 \mathrm{mg}$ at Weeks 0, 2 and 4) for 48 weeks. Patients who achieved sustained remission in this period were eligible to enter the second part of the trial (maintenance period; Weeks 48 to 96). Sustained remission was defined as Ankylosing Spondylitis Disease Activity Score ${ }^{15} 16$ (ASDAS) inactive disease (ASDAS-ID: ASDAS <1.3) at Week 32 or 36, and at Week 48 (with ASDAS <2.1 for Weeks 32 and 36).

The maintenance period (Weeks 48 to 96) was a randomised, parallel-group, double-blind, placebo-controlled 48-week study period, which evaluated the efficacy and safety of CZP in patients with sustained remission who received CZP $200 \mathrm{mg}$ Q2W (full maintenance dose), CZP 200 mg every 4 weeks (Q4W; reduced maintenance dose) or placebo. Randomisation (1:1:1) was stratified by geographical region and presence or absence of radiographic sacroiliitis. The primary outcome was remaining flare-free during the maintenance period. Flare was defined as: ASDAS $\geq 2.1$ (high disease activity) at two consecutive visits, or ASDAS $>3.5$ (very high disease activity) at any visit.

The maintenance period included an early escape arm for those patients who experienced a flare. Patients who escaped received open-label CZP $200 \mathrm{mg}$ Q2W for a minimum of 12 weeks to assess possible return to clinical remission. Those escaping from the placebo arm received a loading dose of CZP $400 \mathrm{mg}$ at 0,2 and 4 weeks into the escape arm.

\section{Patient and public involvement}

Patients were not involved in the study design or conduct. A lay summary reporting study outcomes will be made available on the study sponsor website approximately 1 year after the last patient assessment.

\section{Patients}

Patients eligible for inclusion were 18 to 45 years of age, had a documented diagnosis of axSpA (starting at age 18 or older) meeting the Assessment of SpondyloArthritis international Society (ASAS) classification criteria, ${ }^{17}$ symptom duration $\geq 3$ months and $<5$ years and active disease (defined as ASDAS $\geq 2$.1, Bath Ankylosing Spondylitis Disease Activity Index (BASDAI) $\geq 4$ and spinal pain $\geq 4$ on a 0 to 10 numerical rating scale (BASDAI item 2)).

Patients were subclassified as having either radiographic axSpA (fulfilling the imaging criterion of the modified New York classification criteria $^{18}$ (radiographic sacroiliitis was confirmed by two central readers, plus an adjudicator if necessary)) or non-radiographic axSpA (fulfilling the ASAS but not the modified New York criteria imaging criterion). In addition, patients with non-radiographic axSpA had to have either a C-reactive protein level above the upper limit of normal or evidence of active sacroiliitis on MRI (using ASAS/Outcome Measures in Rheumatology (OMERACT) definition of a positive MRI, confirmed by two central readers and an adjudicator if necessary). All patients must have had inadequate response, contraindication or intolerance to $\geq 2$ non-steroidal anti-inflammatory drugs. Permitted concomitant medications included stable doses of certain analgesics, non-steroidal anti-inflammatory drugs and disease-modifying anti-rheumatic drugs (online supplementary table S1).

Full patient selection criteria are provided in the online supplementary appendix. All patients provided informed consent to participate.

\section{Outcome measures}

The primary outcome of the C-OPTIMISE study was the percentage of patients remaining flare-free during the maintenance period; the main secondary outcome was time to flare. Additional key secondary outcomes included the percentage of patients achieving sustained remission at Week 48, and assessment of disease activity at Week 96. Disease activity measures included assessment of ASDAS status (ASDAS-ID, low disease activity, high disease activity and very high disease activity), ${ }^{16}$ ASDAS major improvement (MI; ASDAS reduction from baseline of $\geq 2.0$ ) and clinically important improvement (CII; ASDAS reduction from baseline of $\geq 1.1$ ), ${ }^{16}$ ASAS response (ASAS20, ASAS40, ASAS5/6), ASAS partial remission, ${ }^{19} 20$ BASDAI50 response and change from maintenance period baseline (Week 48 ) in ASDAS, BASDAI, ${ }^{21}$ Bath Ankylosing Spondylitis Functional Index (BASFI), ${ }^{22}$ Bath Ankylosing Spondylitis Metrology Index (BASMI; linear definition) ${ }^{23}{ }^{24}$ and MRI outcomes, including sacroiliac joint Spondyloarthritis Research Consortium of Canada (SIJ SPARCC) score $^{25}$ and the Berlin modification of the Ankylosing Spondylitis spine MRI score for activity (ASspiMRI-a). ${ }^{26}$

Additional outcomes included assessment at Week 96 of Maastricht Ankylosing Spondylitis Enthesitis Score ${ }^{27}$ and tender and swollen joint counts (44 joints evaluation). For patients who experienced a flare during the maintenance period, outcomes at 12 weeks after escape to open-label CZP $200 \mathrm{mg}$ Q2W are reported.

All treatment-emergent adverse events (TEAEs) were reported for the Safety Set (patients who received $\geq 1$ dose CZP) up to 70 days after the last dose of study medication. TEAEs were coded according to Medical Dictionary for Regulatory Activities (MedDRA) V.19.0. 
A

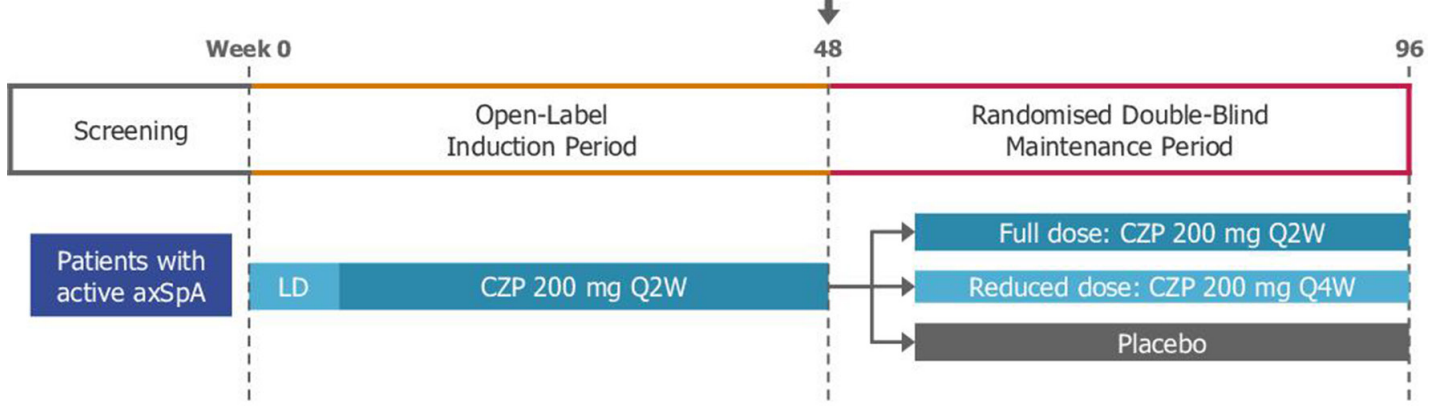

$\mathbf{B}$

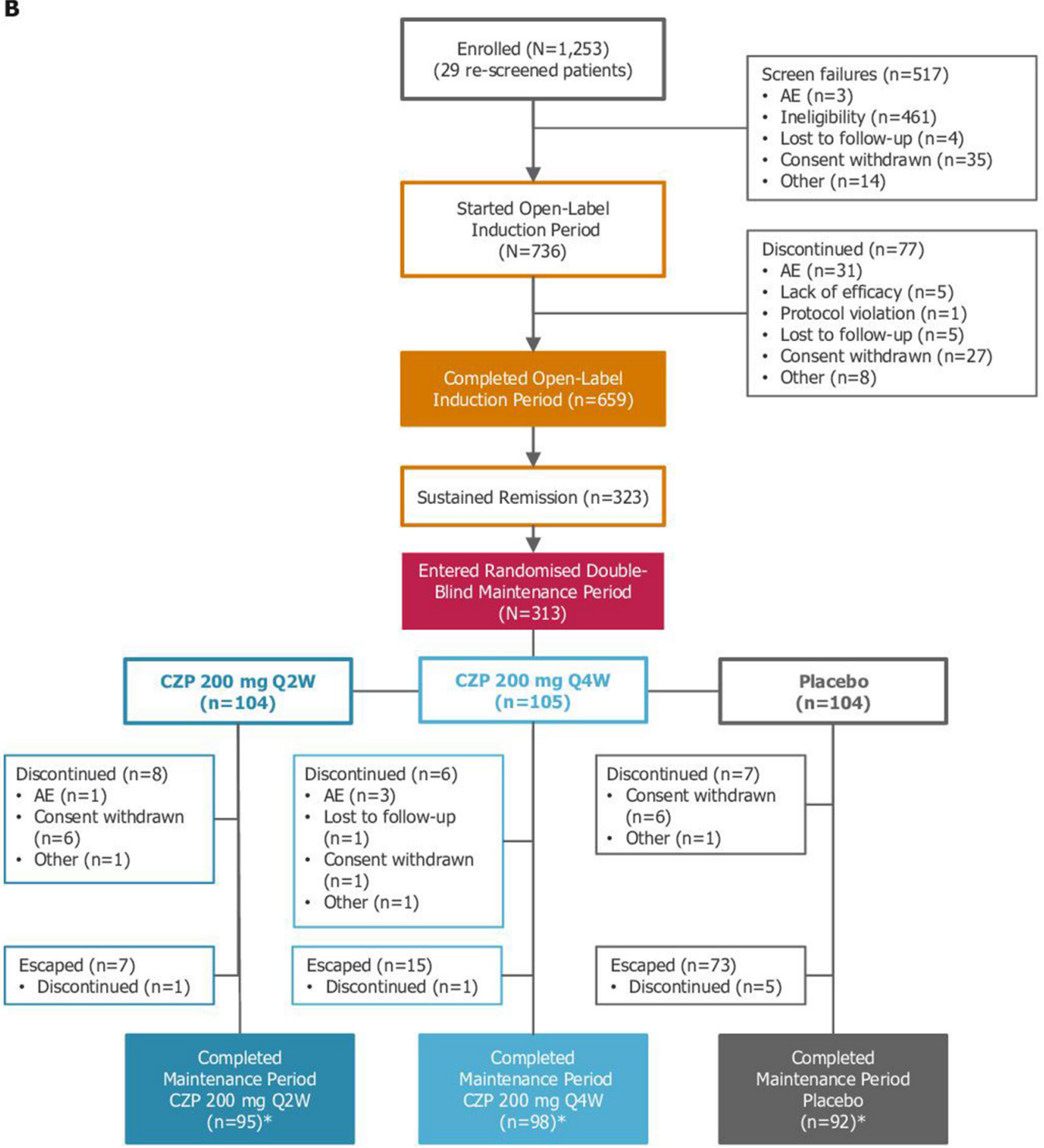

Figure 1 C-OPTIMISE study design (panel A) and patient disposition (panel B). AE, adverse event; axSpA, axial spondyloarthritis; CZP, certolizumab pegol; LD, loading dose; Q2W, every 2 weeks; Q4W, every 4 weeks. *Includes patients in the escape arm who completed week 96.

\section{Study procedures and evaluations}

Outcomes were assessed during study visits, scheduled for Weeks $2,4,12,24,32,36,48,52,60,72,84$ and 96 . During the maintenance period, ASDAS (used to define disease flare) was evaluated at Weeks 48, 50, 52, then every 4 weeks up to Week 96. For patients escaping to open-label treatment after experiencing a flare in the maintenance period, ASDAS components were assessed at 0,2 and 4 weeks into the escape arm, then every 4 weeks up to Week 96.

\section{Statistical analysis}

Assuming that $80 \%, 75 \%$ and $45 \%$ of CZP $200 \mathrm{mg}$ Q2W, CZP $200 \mathrm{mg}$ Q4W and placebo patients, respectively, would remain 
Table 1 Demographics and disease characteristics for patients enrolled in C-OPTIMISE

\begin{tabular}{|c|c|c|c|c|}
\hline & \multirow{2}{*}{$\begin{array}{l}\begin{array}{l}\text { Induction } \\
\text { period }\end{array} \\
\text { All axSpA } \\
(\mathrm{n}=736)\end{array}$} & \multicolumn{3}{|c|}{$\begin{array}{l}\text { Patients randomised into maintenance } \\
\text { period } \\
(\mathrm{n}=313)\end{array}$} \\
\hline & & $\begin{array}{l}\text { CZP } 200 \mathrm{mg} \\
\text { Q2W } \\
(\mathrm{n}=104)\end{array}$ & $\begin{array}{l}\text { CZP } 200 \mathrm{mg} \\
\text { Q4W } \\
(n=105)\end{array}$ & $\begin{array}{l}\text { Placebo } \\
(n=104)\end{array}$ \\
\hline \multicolumn{5}{|l|}{$\begin{array}{l}\text { Baseline } \\
\text { demographics }\end{array}$} \\
\hline \multicolumn{5}{|l|}{ Age, years } \\
\hline Mean (SD) & $32.9(7.0)$ & $32.6(7.2)$ & $32.4(6.9)$ & $31.2(6.6)$ \\
\hline Range & $18-45$ & $18-45$ & $18-45$ & $18-45$ \\
\hline Male, $\mathrm{n}(\%)$ & $514(69.8)$ & $79(76.0)$ & $83(79.0)$ & $85(81.7)$ \\
\hline BMI, kg/m², mean (SD) & $25.7(4.9)$ & $25.1(4.2)$ & $25.9(4.6)$ & $24.7(3.6)$ \\
\hline \multicolumn{5}{|l|}{ Race, n (\%) } \\
\hline Caucasian & $681(92.5)$ & $97(93.3)$ & $97(92.4)$ & $98(94.2)$ \\
\hline Asian & $38(5.2)$ & $5(4.8)$ & $6(5.7)$ & $5(4.8)$ \\
\hline Other/mixed/missing & $17(2.3)$ & $2(1.9)$ & $2(1.9)$ & $1(1.0)$ \\
\hline \multicolumn{5}{|c|}{$\begin{array}{l}\text { Geographical region, } \\
\mathrm{n}(\%)\end{array}$} \\
\hline North America & $33(4.5)$ & $3(2.9)$ & $3(2.9)$ & $4(3.8)$ \\
\hline Western Europe & $91(12.4)$ & $10(9.6)$ & $9(8.6)$ & $8(7.7)$ \\
\hline Eastern Europe & $537(73.0)$ & $82(78.8)$ & $83(79.0)$ & $82(78.8)$ \\
\hline Asia & $75(10.2)$ & $9(8.7)$ & $10(9.5)$ & $10(9.6)$ \\
\hline mNY positive, n (\%) & $407(55.3)$ & $56(53.8)$ & $56(53.3)$ & $56(53.8)$ \\
\hline \multicolumn{5}{|l|}{$\begin{array}{l}\text { Symptom duration, } \\
\text { years }\end{array}$} \\
\hline Mean (SD) & $3.3(2.2)$ & $3.8(2.8)$ & $3.4(1.8)$ & $3.1(1.6)$ \\
\hline Median & 3.5 & 3.9 & 3.5 & 3.3 \\
\hline \multicolumn{5}{|l|}{$\begin{array}{l}\text { Time since diagnosis, } \\
\text { years }\end{array}$} \\
\hline Mean (SD) & $2.2(1.7)$ & $2.5(1.7)$ & $2.0(1.7)$ & $2.1(1.7)$ \\
\hline Median & 1.6 & 2.7 & 1.3 & 1.3 \\
\hline HLA-B27 positive, $n(\%)$ & $617(83.8)$ & $91(87.5)$ & 97 (92.4) & $94(90.4)$ \\
\hline CRP > ULN, n (\%) & $344(46.7)$ & $55(52.9)$ & $51(48.6)$ & $44(42.3)$ \\
\hline $\begin{array}{l}\text { Prior TNFi therapy, } \\
\mathrm{n}(\%)\end{array}$ & $32(4.3)$ & $4(3.8)$ & $6(5.7)$ & $7(6.7)$ \\
\hline $\begin{array}{l}\text { History of enthesitis } \\
\text { (heel), } \mathrm{n}(\%)\end{array}$ & $184(25.0)$ & $30(28.8)$ & $35(33.3)$ & $24(23.1)$ \\
\hline \multicolumn{5}{|l|}{ History of EAMs, $n(\%)$} \\
\hline Uveitis & $111(15.1)$ & $16(15.4)$ & $20(19.0)$ & $17(16.3)$ \\
\hline $\begin{array}{l}\text { Inflammatory bowel } \\
\text { disease }\end{array}$ & $17(2.3)$ & $2(1.9)$ & $3(2.9)$ & $1(1.0)$ \\
\hline Psoriasis & $45(6.1)$ & $8(7.7)$ & $2(1.9)$ & $7(6.7)$ \\
\hline \multicolumn{5}{|l|}{$\begin{array}{l}\text { Concomitant } \\
\text { medication, }{ }^{*} \mathrm{n}(\%)\end{array}$} \\
\hline NSAIDs & $618(84.0)$ & $85(81.7)$ & $92(87.6)$ & $85(82.5)$ \\
\hline DMARDs & 166 (22.6) & $21(20.2)$ & 24 (22.9) & $24(23.3)$ \\
\hline
\end{tabular}

\section{Disease}

characteristics at

Week 0, mean (SD)

\begin{tabular}{lllll} 
ASDAS & $3.7(0.8)$ & $3.7(0.7)$ & $3.7(0.8)$ & $3.5(0.8)$ \\
\hline BASDAI & $6.7(1.4)$ & $6.5(1.4)$ & $6.7(1.5)$ & $6.3(1.3)$ \\
\hline BASFI & $5.3(2.1)$ & $5.2(1.8)$ & $5.3(2.1)$ & $4.8(1.9)$ \\
\hline BASMI & $3.1(1.5)$ & $3.0(1.3)$ & $2.8(1.4)$ & $2.8(1.6)$ \\
\hline Tender joint count & $2.6(5.0)$ & $1.6(2.9)$ & $2.5(4.1)$ & $1.9(3.6)$ \\
\hline Swollen joint count† & $0.7(2.1)$ & $0.4(1.3)$ & $0.8(1.7)$ & $0.7(1.6)$ \\
\hline MASES & $2.5(3.0)$ & $2.1(2.8)$ & $2.5(3.1)$ & $1.7(2.5)$ \\
\hline Imaging (MRI) & & & & \\
\hline \multicolumn{1}{r}{ SIJ SPARCC } & $8.0(11.4)$ & $8.4(11.6)$ & $10.9(12.5)$ & $9.4(14.3)$ \\
\hline
\end{tabular}

Continued
Table 1 Continued

\begin{tabular}{|c|c|c|c|c|}
\hline & \multirow{2}{*}{$\begin{array}{l}\begin{array}{l}\text { Induction } \\
\text { period }\end{array} \\
\text { All axSpA } \\
(\mathrm{n}=736)\end{array}$} & \multicolumn{3}{|c|}{$\begin{array}{l}\text { Patients randomised into maintenance } \\
\text { period } \\
(\mathrm{n}=313)\end{array}$} \\
\hline & & $\begin{array}{l}\text { CZP } 200 \mathrm{mg} \\
\text { Q2W } \\
(n=104)\end{array}$ & $\begin{array}{l}\text { CZP 200 mg } \\
\text { Q4W } \\
(n=105)\end{array}$ & $\begin{array}{l}\text { Placebo } \\
(n=104)\end{array}$ \\
\hline ASspiMRI-a & $3.1(5.2)$ & $3.5(6.0)$ & $2.9(5.0)$ & $3.2(5.4)$ \\
\hline \multicolumn{5}{|l|}{$\begin{array}{l}\text { Disease } \\
\text { characteristics at } \\
\text { Week } 48 \text {, mean (SD) }\end{array}$} \\
\hline ASDAS & - & $0.8(0.2)$ & $0.8(0.2)$ & $0.8(0.2)$ \\
\hline BASDAI & - & $0.4(0.5)$ & $0.4(0.5)$ & $0.5(0.6)$ \\
\hline BASFI & - & $0.4(0.5)$ & $0.3(0.5)$ & $0.5(0.7)$ \\
\hline BASMI & - & $2.1(1.2)$ & $1.9(1.2)$ & $2.2(1.5)$ \\
\hline Tender joint count & - & $0.2(0.6)$ & $0.1(0.5)$ & $0.2(0.6)$ \\
\hline Swollen joint countt & - & $0.0(0.1)$ & $0.0(0.2)$ & $0.0(0.1)$ \\
\hline MASES & - & $0.1(0.5)$ & $0.1(0.4)$ & $0.3(1.3)$ \\
\hline Imaging (MRI) & - & & & \\
\hline SIJ SPARCC & - & $1.0(2.4)$ & $1.1(2.9)$ & $0.7(1.6)$ \\
\hline ASspiMRI-a & - & $0.7(1.5)$ & $0.7(1.6)$ & $0.5(1.3)$ \\
\hline
\end{tabular}

*Any intake during induction period (Weeks 0 to 48 ) or maintenance period (Weeks 48 to 96$)$.

†44 joints.

ASDAS, Ankylosing Spondylitis Disease Activity Score; ASspiMRI-a, Ankylosing Spondylitis spine MRI score for activity; axSpA, axial spondyloarthritis; BASDAl, Bath Ankylosing Spondylitis Disease Activity Index; BASFI, Bath Ankylosing Spondylitis Functional Index; BASMI, Bath Ankylosing Spondylitis Metrology Index; BMI, body mass index; CRP, C-reactive protein; CZP, certolizumab pegol; DMARD, diseasemodifying anti-rheumatic drug; EAMs, extra-articular manifestations; HLA-B27, human leucocyte antigen-B27; MASES, Maastricht Ankylosing Spondylitis Enthesitis Score; mNY, modified New York; NSAID, non-steroidal anti-inflammatory drug; Q2W, every 2 weeks; Q4W, every 4 weeks; SIJ SPARCC, sacroiliac joint Spondyloarthritis Research Consortium of Canada; TNFi, tumour necrosis factor inhibitor; ULN, upper limit of normal.

flare-free during the 48 -week maintenance period, a sample size of 210 patients was deemed sufficient to provide $98 \%$ power to detect a difference between CZP $200 \mathrm{mg}$ Q2W versus placebo, and $94 \%$ power for CZP $200 \mathrm{mg}$ Q4W versus placebo, using a two-sided significance level of 0.05 . Based on the assumption that $\sim 28 \%$ of patients would achieve sustained remission at the end of the induction period, 750 patients were planned for study enrolment.

The primary analysis was based on a logistic regression model which included treatment group, region and presence or absence of radiographic sacroiliitis as factors. ORs for each CZP dose versus placebo (with 95\% two-sided CIs) were derived from the model, based on the percentage of patients who did not experience a flare. A fixed sequence testing procedure was used to account for testing of multiple doses: hypothesis testing at the 0.05 level was first conducted for CZP $200 \mathrm{mg}$ Q2W versus placebo, followed by CZP $200 \mathrm{mg}$ Q4W versus placebo. The second test was only interpreted as statistically significant if the first test was significant at the 0.05 level. No statistical testing was planned for CZP $200 \mathrm{mg}$ Q2W versus CZP $200 \mathrm{mg}$ Q4W.

Non-responder imputation (NRI) was used to account for missing data for analysis of the primary outcome; if patients withdrew or had two consecutive missing ASDAS values these were designated as flares. The time to flare was analysed using the log-rank test and Kaplan-Meier methods. The percentage of patients achieving sustained remission is summarised using descriptive statistics (counts and percentages). Continuous data are summarised using mean and SD. In the maintenance period, 
A

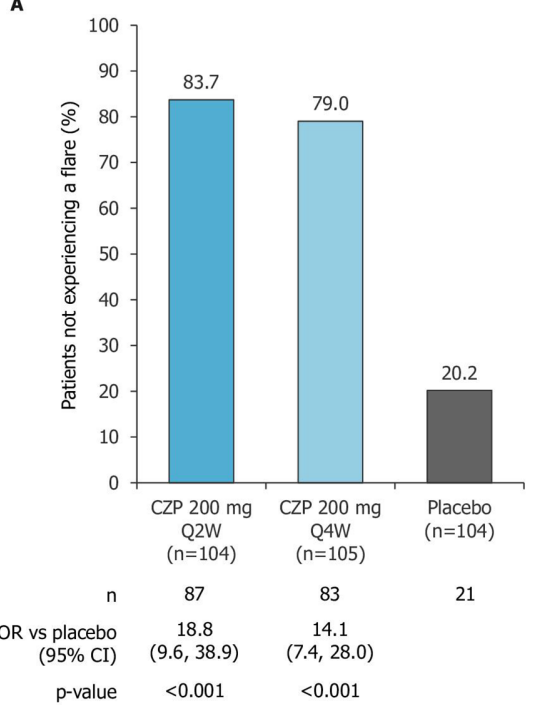

B

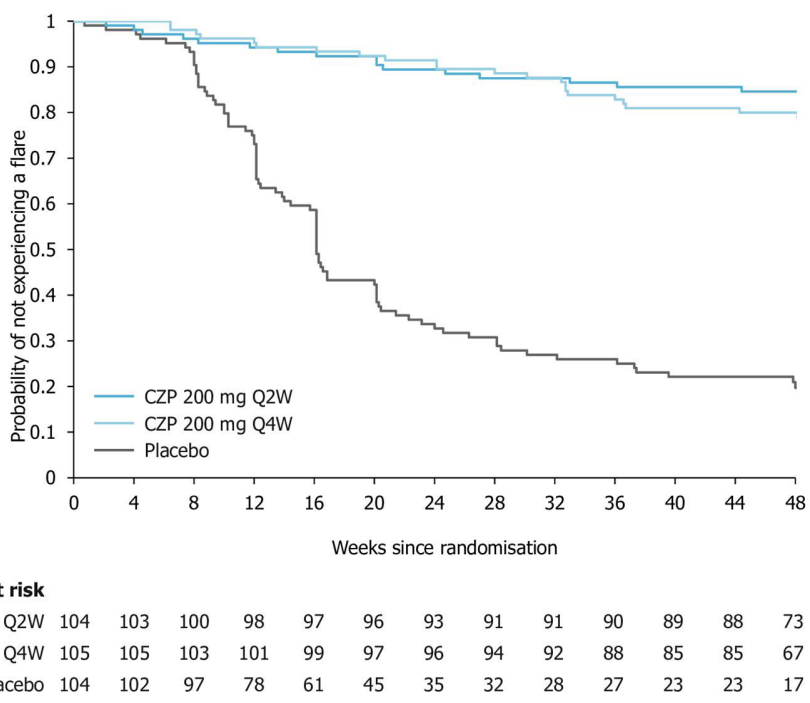

Figure 2 Patients free of flares during the maintenance period of C-OPTIMISE. Panel A shows the proportions of patients who did not experience flares following randomisation to CZP full maintenance dose (200 mg Q2W), CZP reduced maintenance dose (200 mg Q4W) or placebo. Panel B shows a Kaplan-Meier plot of time to flare. Missing values were imputed using non-responder imputation. Flare was defined as ASDAS $\geq 2.1$ at two consecutive visits, or ASDAS >3.5 at any visit. CZP, certolizumab pegol; Q2W, every 2 weeks; Q4W, every 4 weeks.

binary variables were analysed using logistic regression (using NRI to impute missing values), and continuous data were analysed using a mixed model for repeated measures. For patients entering the escape arm, ASDAS status and ASDAS clinical responses (calculated from the start of escape medication) are reported using descriptive statistics.

Post-hoc analysis of predictors of flare was performed using a stepwise logistic regression model (details in online supplementary material).

Statistical analyses were performed using SAS Version 9.3.

\section{RESULTS}

\section{Patient disposition and baseline characteristics}

Of 1253 patients screened, 736 were enrolled into the induction part of C-OPTIMISE, including 407 patients with radiographic axSpA and 329 with non-radiographic axSpA (figure 1). The mean age at study entry was 32.9 years, with an average symptom duration of 3.3 years (table 1 ). Baseline characteristics were comparable between radiographic and non-radiographic axSpA, but the former included a higher percentage of patients who were male, humanleucocyte antigen-B27 (HLA-B27)

\section{Radiographic axSpA}

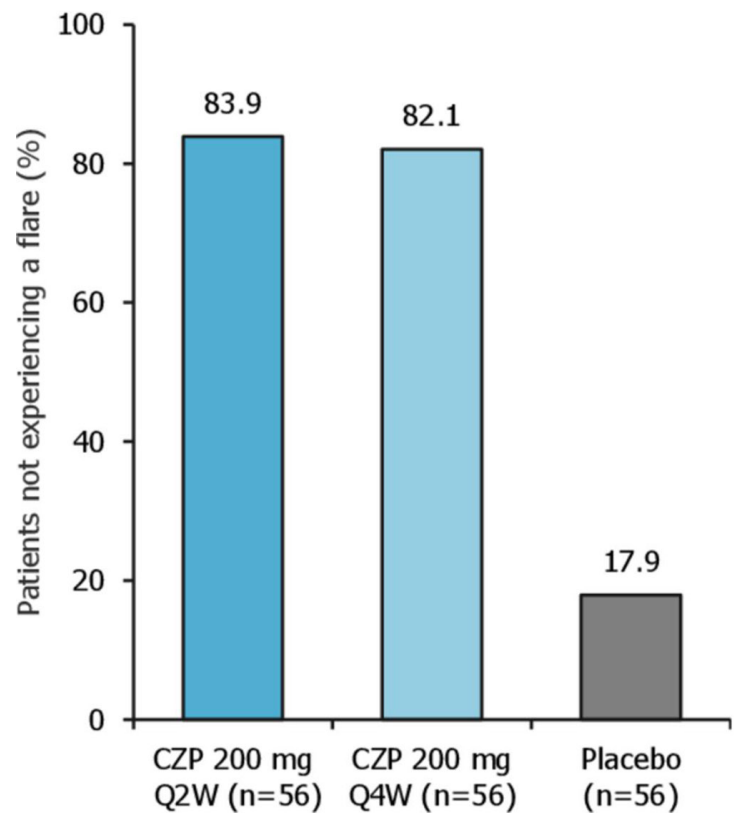

\section{Non-radiographic axSpA}

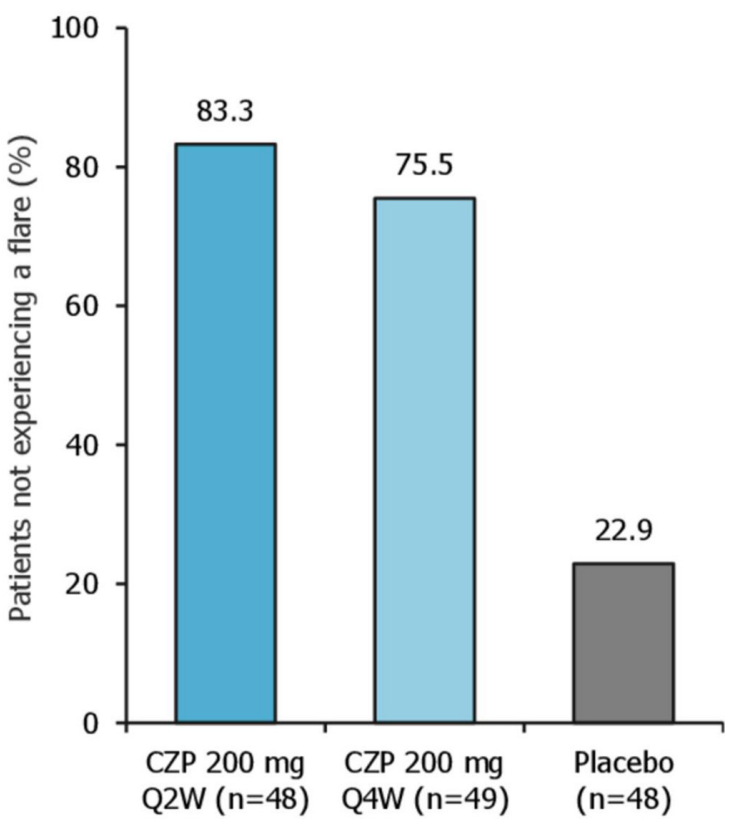

Figure 3 Patients with radiographic and non-radiographic axial spondyloarthritis not experiencing flares during the maintenance period of $\mathrm{C}$ OPTIMISE. axSpA, axial spondyloarthritis; CZP, certolizumab pegol; Q2W, every 2 weeks; Q4W, every 4 weeks. 
Table 2 Efficacy outcomes at the end of the maintenance period (Week 96) of C-OPTIMISE ( $n=313)$

\begin{tabular}{|c|c|c|c|c|c|c|}
\hline & Imputation & $\begin{array}{l}\text { CZP 200 mg Q2W } \\
(n=104)\end{array}$ & P vs placebo & $\begin{array}{l}\text { CZP 200 mg Q4W } \\
(n=105)\end{array}$ & P vs placebo & $\begin{array}{l}\text { Placebo } \\
(n=104)\end{array}$ \\
\hline \multicolumn{7}{|c|}{ ASDAS disease activity state, $\mathrm{n}(\%)$} \\
\hline $\operatorname{ID}(<1.3)$ & OC & $75 / 87(86.2)$ & - & $58 / 83(69.9)$ & - & $14 / 24(58.3)$ \\
\hline $\mathrm{LD}(\geq 1.3$ and $<2.1)$ & $\mathrm{OC}$ & $12 / 87(13.8)$ & - & $19 / 83(22.9)$ & - & $6 / 24(25.0)$ \\
\hline$H D(\geq 2.1$ and $\leq 3.5)$ & OC & $0 / 87(0)$ & - & $6 / 83(7.2)$ & - & $4 / 24(16.7)$ \\
\hline $\mathrm{vHD}(>3.5)$ & OC & $0 / 87(0)$ & - & $0 / 83(0)$ & - & $0 / 24(0)$ \\
\hline \multicolumn{7}{|c|}{ Disease activity responses from Week $0, n(\%)$} \\
\hline \multicolumn{7}{|c|}{ ASDAS clinical improvement* } \\
\hline $\mathrm{Cll}$ & NRI & $86(82.7)$ & $<0.001$ & $79(75.2)$ & $<0.001$ & $22(21.2)$ \\
\hline $\mathrm{Ml}$ & NRI & $70(67.3)$ & $<0.001$ & $61(58.1)$ & $<0.001$ & $11(10.6)$ \\
\hline \multicolumn{7}{|l|}{ ASAS responder rates* } \\
\hline 20 & NRI & $89(85.6)$ & $<0.001$ & $82(78.1)$ & $<0.001$ & $24(23.1)$ \\
\hline 40 & NRI & $88(84.6)$ & $<0.001$ & $77(73.3)$ & $<0.001$ & $22(21.2)$ \\
\hline $5 / 6$ & NRI & $73(70.2)$ & $<0.001$ & $66(62.9)$ & $<0.001$ & $13(12.5)$ \\
\hline Partial remission & NRI & $81(77.9)$ & $<0.001$ & $74(70.5)$ & $<0.001$ & $18(17.3)$ \\
\hline BASDAI50 $0^{\mathrm{a}}$ & NRI & $87(83.7)$ & $<0.001$ & $81(77.1)$ & $<0.001$ & $23(22.1)$ \\
\hline \multicolumn{7}{|c|}{ Change from Week 48} \\
\hline \multicolumn{7}{|c|}{ Efficacy outcomes, LS mean \pm SE } \\
\hline ASDAS & MMRM & $0.2 \pm 0.1$ & $<0.001$ & $0.5 \pm 0.1$ & $<0.001$ & $1.7 \pm 0.1$ \\
\hline BASDAI & MMRM & $0.6 \pm 0.2$ & $<0.001$ & $0.8 \pm 0.2$ & $<0.001$ & $3.0 \pm 0.2$ \\
\hline BASFI & MMRM & $0.3 \pm 0.2$ & $<0.001$ & $0.5 \pm 0.2$ & $<0.001$ & $1.9 \pm 0.2$ \\
\hline BASMI & MMRM & $0.0 \pm 0.1$ & 0.074 & $-0.0 \pm 0.1$ & 0.036 & $0.2 \pm 0.1$ \\
\hline \multicolumn{7}{|c|}{ MRI outcomes, mean (SD; n) } \\
\hline SIJ SPARCC score & $\mathrm{OC}$ & $0.2(2.4 ; 79)$ & 0.195 & $0.6(3.8 ; 77)$ & 0.432 & $1.1(3.6 ; 24)$ \\
\hline ASspiMRI-a & $\mathrm{OC}$ & $0.0(0.8 ; 79)$ & 0.040 & $0.0(0.8 ; 78)$ & 0.074 & $0.4(0.9 ; 24)$ \\
\hline \multicolumn{7}{|c|}{ Additional outcomes, mean $(S D ; n)$} \\
\hline MASES & $\mathrm{OC}$ & $0.1(0.6 ; 90)$ & - & $0.1(0.6 ; 84)$ & - & $-0.1(0.9 ; 24)$ \\
\hline Tender joint count & $\mathrm{OC}$ & $-0.1(0.6 ; 90)$ & - & $0.1(0.9 ; 84)$ & - & $0.0(1.0 ; 24)$ \\
\hline Swollen joint count & $\mathrm{OC}$ & $0.0(0.2 ; 90)$ & - & $0.0(0.2 ; 84)$ & - & $0.0(0.0 ; 24)$ \\
\hline
\end{tabular}

$\mathrm{P}$ values were obtained using a logistic regression model or, for MRI outcomes, an ANCOVA model, with factors for treatment group, geographical region and mNY classification (Week 48 baseline was included as a covariate in the ANCOVA model).

${ }^{*}$ Calculated from Week 0 baseline.

ANCOVA, analysis of covariance; ASAS, Assessment of Spondyloarthritis international Society; ASDAS, Ankylosing Spondylitis Disease Activity Score; ASDAS-ID/LD/HD/vHD, ASDAS-inactive disease/low disease/high disease/very high disease; ASspiMRI-a, Ankylosing Spondylitis spine MRI score for activity; BASDAI50, Bath Ankylosing Spondylitis Disease Activity Index 50\% improvement; BASFI, Bath Ankylosing Spondylitis Functional Index; BASMI, Bath Ankylosing Spondylitis Metrology Index; CII, clinically important improvement; CZP, certolizumab pegol; LS, least squares; MASES, Maastricht Ankylosing Spondylitis Enthesitis Score; MI, major improvement; MMRM, mixed effect model for repeated measures; mNY, modified New York; NRI, non-responder imputation; OC, observed case; Q2W, every 2 weeks; Q4W, every 4 weeks; SIJ SPARCC, sacroiliac joint Spondyloarthritis Research Consortium of Canada.

positive and with elevated C-reactive protein (CRP) levels (online supplementary table S2).

By Week 48, 323 patients had achieved sustained remission. Of these, 313 underwent 1:1:1 randomisation: 104 were randomised to CZP full maintenance dose, 105 to CZP reduced maintenance dose and 104 to placebo. A further 10 patients with sustained remission did not enter the maintenance period due to subject withdrawal or ineligibility. Compared with patients who entered the induction period, those entering the maintenance period were more likely to be male and HLA-B27 positive. Week 48 disease characteristics were similar among patients entering the maintenance period (table 1).

\section{Efficacy}

\section{Induction period}

During the 48-week induction period in which patients received open-label CZP $200 \mathrm{mg}$ Q2W treatment, $43.9 \%$ of patients (323/736) achieved sustained remission according to the study definition. Results were similar among patients with radiographic and non-radiographic axSpA: $42.8 \%(174 / 407)$ and $45.3 \%(149 / 329)$ achieved sustained remission, respectively.

\section{Maintenance period}

During the maintenance period, $83.7 \%(87 / 104)$ and $79.0 \%$ of patients (83/105) who were randomised to the CZP full maintenance dose or CZP reduced maintenance dose, respectively, remained flare-free. Only $20.2 \%$ of patients (21/104) randomised to placebo remained flare-free $(\mathrm{p}<0.001 \mathrm{vs}$ placebo for both CZP maintenance doses; figure $2 \mathrm{~A}$ ). The time to flare was significantly different for each CZP dose versus placebo $(p<0.001$ vs placebo for both CZP treatment groups, log-rank test). In the placebo arm, the median time to flare following randomisation was 113 days (95\% CI: 101 to 141$)$, with the majority of flares occurring between 8 and 20 weeks post-randomisation (figure 2B). For CZP patients, no median time to flare could be determined within the 48-week timeframe. Among patients with radiographic or non-radiographic axSpA, similar percentages of patients did not experience flares (figure 3).

Post-hoc logistic regression analysis of predictors of flares in CZP (full and reduced maintenance dose groups combined) and placebo patients identified HLA-B27 negativity as a potential predictor of flares in patients randomised to CZP, but not in those randomised to placebo (online supplementary table 
S3). The model did not identify any other variables as possible predictors of flare.

\section{Escape arm}

During the maintenance period, 95 patients who experienced flares (7 randomised to CZP full maintenance dose, 15 to CZP reduced maintenance dose and 73 to placebo) entered an openlabel escape arm. The mean (SD) ASDAS at the time of flare for patients in the CZP full and reduced maintenance dose groups was 2.5 (1.1) and $2.3(0.6)$, respectively, while in the placebo group ASDAS was 3.4 (1.0). Twelve weeks after treatment re-initiation with open-label CZP $200 \mathrm{mg}$ Q2W following flare, clinical remission (ASDAS-ID) was regained in 63.4\% $(45 / 71)$, $60.0 \%(9 / 15)$ and $16.7 \%(1 / 6)$ of patients escaping from the placebo, CZP reduced maintenance dose and CZP full maintenance dose arms, respectively. An ASDAS <2.1 (ASDAS low disease activity) was reached in $90.1 \%(64 / 71), 80.0 \%(12 / 15)$ and $66.7 \%(4 / 6)$ of patients, respectively. For other efficacy measures, including BASDAI, BASFI and SIJ SPARCC, disease activity was highest in the placebo group at the time of flare, but showed improvements after 12 weeks of escape treatment (online supplementary table S4).

\section{Other efficacy outcomes}

At Week 96, a significantly higher percentage of patients randomised to the CZP full or reduced maintenance dose achieved an ASDAS clinical improvement (CII or MI), ASAS20/40 or BASDAI50 response compared with placebo (table 2), with responses calculated from Week 0 .

Between Weeks 48 and 96, in patients randomised to the CZP full or reduced maintenance dose, disease activity (ASDAS and BASDAI), function (BASFI) and mobility (BASMI) remained stable (table 2). In patients randomised to placebo, disease activity (ASDAS and BASDAI) and function (BASFI) worsened between Weeks 48 and 96 (table 2).

In all three treatment groups, there were minimal changes in MRI outcomes (SIJ SPARCC and ASspiMRI-a) in patients who remained on randomised treatment (table 2).

\section{Safety}

During the maintenance period, TEAEs were reported in $57.7 \%$, $61.0 \%$ and $54.4 \%$ of patients randomised to CZP $200 \mathrm{mg}$ Q2W, CZP $200 \mathrm{mg}$ Q4W or placebo, respectively (table 3). Serious TEAEs were reported in five patients randomised to CZP $200 \mathrm{mg}$ Q2W: these included one case each of acute pancreatitis, Crohn's disease and anal abscess, which the study investigators did not consider to be treatment-related, and one case each of intestinal obstruction and latent tuberculosis, which were considered by the study investigators to be treatment-related. No serious TEAEs led to patient withdrawal from the study, and complete recovery was reported for all five cases. There were no malignancies, serious cardiovascular events or deaths during the study.

\section{DISCUSSION}

C-OPTIMISE demonstrates that patients with early axSpA who achieve sustained remission after 48 weeks' full dose CZP (200 mg Q2W) treatment can reduce their dose without further increasing their risk of flares in disease activity, but that they should not completely stop treatment. This is an important finding for clinicians who face decisions on how best to manage axSpA patients in sustained remission. These results also have implications for patients, who are typically in their late 20 s or
Table 3 Treatment-emergent adverse events during the C-OPTIMISE maintenance period (Weeks 48 to 96)

\begin{tabular}{|c|c|c|c|}
\hline $\begin{array}{l}\mathrm{N}(\%) \text {, unless } \\
\text { otherwise specified }\end{array}$ & $\begin{array}{l}\text { CZP } 200 \mathrm{mg} \\
\text { Q2W } \\
(\mathrm{n}=104)\end{array}$ & $\begin{array}{l}\text { CZP } 200 \mathrm{mg} \\
\text { Q4W } \\
(n=105)\end{array}$ & $\begin{array}{l}\text { Placebo } \\
(n=104)\end{array}$ \\
\hline \multicolumn{4}{|l|}{$\begin{array}{l}\text { CZP exposure duration } \\
\text { (days) }\end{array}$} \\
\hline Mean (SD) & $306.9(78.9)$ & $300.5(77.7)$ & $171(104.7)$ \\
\hline Median (range) & 336.0 (14 to 346$)$ & 336.0 (44 to 350 ) & 126.0 (14 to 345$)$ \\
\hline Total patient-years at risk & 101.0 & 96.4 & 52.7 \\
\hline Any TEAE & $60(57.7)$ & $64(61.0)$ & $56(54.4)$ \\
\hline Event rate per $100 \mathrm{PY}$ & 177.2 & 140.0 & 237.1 \\
\hline Serious TEAEs & $5(4.8)$ & 0 & 0 \\
\hline $\begin{array}{l}\text { Discontinuation due to } \\
\text { TEAEs }\end{array}$ & $1(1.0)$ & $3(2.9)$ & 0 \\
\hline Drug-related TEAEs & $14(13.5)$ & $20(19.0)$ & $14(13.6)$ \\
\hline Severe TEAEs & $1(1.0)$ & 0 & $2(1.9)$ \\
\hline \multicolumn{4}{|l|}{ TEAEs of Interest } \\
\hline $\begin{array}{l}\text { Opportunistic } \\
\text { infections }\end{array}$ & $1(1.0)$ & $3(2.9)$ & $2(1.9)$ \\
\hline Oral candidiasis & 0 & $1(1.0)$ & 0 \\
\hline $\begin{array}{l}\text { Malignant or } \\
\text { unspecified tumours* }\end{array}$ & 0 & 0 & 0 \\
\hline $\begin{array}{l}\text { Serious cardiovascular } \\
\text { eventst }\end{array}$ & 0 & 0 & 0 \\
\hline $\begin{array}{l}\text { Serious } \\
\text { haematopoietic } \\
\text { cytopenia }\end{array}$ & 0 & 0 & 0 \\
\hline $\begin{array}{l}\text { Serious bleeding } \\
\text { events } \ddagger\end{array}$ & 0 & 0 & 0 \\
\hline Hepatic events§ & $3(2.9)$ & $5(4.8)$ & $3(2.9)$ \\
\hline $\begin{array}{l}\text { Liver function } \\
\text { analyses } \mathbb{}\end{array}$ & $3(2.9)$ & $4(3.8)$ & $2(1.9)$ \\
\hline $\begin{array}{l}\text { Hypersensitivity } \\
\text { and anaphylactic } \\
\text { reactions** }\end{array}$ & 0 & 0 & 0 \\
\hline $\begin{array}{l}\text { Demyelinating } \\
\text { disorders }\end{array}$ & 0 & 0 & 0 \\
\hline Deaths & 0 & 0 & 0 \\
\hline
\end{tabular}

*Identified using SMQs 'malignant or unspecified tumours' and 'malignant tumours'; also include incidence of 'any malignancy'.

tIdentified using study sponsor-defined search criteria based on a two-step process using identification via a predefined list of preferred terms in addition to manual review by the study physician.

fldentified using SMQ 'haemorrhage terms (excluding laboratory terms)' in the subset of serious TEAEs.

§Identified using SMQs 'cholestasis and jaundice of hepatic origin', 'hepatic failure, fibrosis and cirrhosis and other liver damage-related conditions', 'hepatitis, noninfectious', 'liver-related investigations, signs and symptoms' and 'liver-related coagulation and bleeding disturbances'.

IIIncludes increased levels of alanine aminotransferase, aspartate aminotransferase, hepatic enzyme, blood bilirubin or transaminases.

** Includes incidence of 'any hypersensitivity and anaphylactic reactions', 'any hypersensitivity reactions' and 'any anaphylactic reactions'. Safety events are reported for the Safety Set $(n=736)$ according to MedDRA Version 19.0.

CZP, certolizumab pegol; MedDRA, Medical Dictionary for Regulatory Activities; PY, patient-years; Q2W, every 2 weeks; Q4W, every 4 weeks; SD, standard deviation; SMQ, standard MedDRA query; TEAE, treatment-emergent adverse event.

early 30 s at symptom onset and who fear long-term continuation of immunosuppressive therapy. Furthermore, the option to reduce the maintenance dose can ease the economic burden of TNFi treatment.

While previous studies have explored TNFi tapering or withdrawal in patients with axSpA following remission 
induction, ${ }^{11} 1228$ C-OPTIMISE is the first randomised controlled trial to compare both dose continuation and reduction with the effects of TNFi withdrawal. In keeping with the results from C-OPTIMISE, ABILITY-3 showed that adalimumab withdrawal led to significantly more flares than continuation; however, there was no comparison with a reduced dose arm in ABILITY-3, which also included only patients with non-radiographic axSpA. ${ }^{11}$ C-OPTIMISE recruited patients with both subforms of axSpA (radiographic and non-radiographic), and patients were on average younger (32.9 vs 37.3 years) and had shorter symptom duration (3.3 vs 7.7 years) compared with ABILITY-3. The induction period of C-OPTIMISE was also longer (48 vs 28 weeks), although in both studies patients had to be in remission (ASDAS-ID) for at least 12 weeks to be eligible for randomisation. In C-OPTIMISE, more patients randomised to CZP (full or reduced dose) maintained remission $(\sim 80 \%)$ compared with ABILITY-3 (70\%); however, in the withdrawal arm more patients in ABILITY-3 maintained remission (47\%) than in C-OPTIMISE (20\%). This difference may be attributable to differences in patient populations. The inclusion of both radiographic and non-radiographic axSpA patients in C-OPTIMISE demonstrated the benefits of dose reduction across the entire axSpA spectrum.

The use of ASDAS-ID $(<1.3)$ as the definition of remission in C-OPTIMISE aligns with recommendations in current treat-to-target guidelines for axSpA. ${ }^{2}$ Additionally, the recently published ASAS-flare definition is based on ASDAS, but was not yet available at the time of the design of the current study. ${ }^{29}$ The advantages of ASDAS are the combination of patient-reported outcomes and an objective measure of inflammation (ie, CRP) as well as validated cut-offs for various levels of disease activity and improvement.

Approximately two-thirds of patients who experienced flares following complete withdrawal of CZP were able to regain their status of remission following 12 weeks of rescue treatment with open-label CZP $200 \mathrm{mg}$ Q2W; similar results were seen for patients escaping from the reduced maintenance dose arm, although patient numbers in this group were smaller. A high proportion of escapers from the placebo arm achieved ASDAS $<2.1(\sim 90 \%)$ after 12 weeks of rescue treatment, so it is possible that with continued treatment beyond 12 weeks more patients would regain their initial response (ASDAS-ID).

Identification of predictors of flare could help to optimise chances of successfully maintaining remission following either dose reduction or withdrawal. Post-hoc analyses in C-OPTIMISE identified HLA-B27 negativity as a possible predictor of flare in patients who continued on CZP treatment, but did not identify any predictors in placebo-randomised patients. Given the small number of flares in the CZP treatment groups, further investigation into this result is required.

No new safety concerns were identified throughout the entire study period. Five serious TEAEs were reported, all of which occurred in patients continuing on the full CZP maintenance dose. A full recovery was made for all five events, including the two serious TEAEs considered by the study investigator to be treatment-related. Nevertheless, this may add to the relevance of TNFi dose reduction in patients when clinically possible.

A potential limitation of the C-OPTIMISE study is the fact that enrolment was limited to patients with $<5$ years' symptom duration, so it is unclear whether the results may be generalised to patients with more established disease.

In summary, in early axSpA patients in sustained remission after 1 year of open-label treatment with CZP, reducing the maintenance dose of CZP enabled patients to maintain their state of remission, while completely stopping treatment resulted in flares in the majority of patients. CZP maintenance dose reduction is therefore a feasible option for the long-term management of this chronic rheumatic disease, which has the advantage of preserving the clinical benefits of remaining on TNFi treatment, reducing costs and limiting patients' long-term exposure to immunosuppressive therapy.

\section{Author affiliations}

${ }^{1}$ Amsterdam Rheumatology \& Clinical Immunology Center, Amsterdam, The Netherlands

${ }^{2}$ Zuyderland Medical Center, Heerlen, The Netherlands

${ }^{3}$ Depertment of Rheumatology, Leiden University Medical Center, Leiden, The Netherlands

${ }^{4}$ Hopital Cochin, Rheumatology, Université Paris Descartes, Paris, France

${ }^{5}$ Rheumazentrum Ruhrgebiet, Ruhr University Bochum, Bochum, Herne, Germany

${ }^{6}$ Department of Internal Medicine and Pediatrics, VIB Center for Inflammation

Research, Ghent University, Ghent, Belgium

${ }^{7}$ Rheumatology Department, Norfolk and Norwich University Hospital NHS Foundation Trust, Norwich, UK

${ }^{8}$ UCB Pharma, Monheim am Rhein, Germany

${ }^{9}$ UCB Pharma, Slough, UK

${ }^{10}$ UCB Pharma, Brussels, Belgium

11University of California San Francisco, San Francisco, California, USA

\section{Twitter Karl Gaffney @KarlGaffney1}

Acknowledgements The authors thank the patients, the investigators and their teams who took part in this study. The authors also acknowledge Christian Stach, UCB Pharma, for contributions to study design, Simone E Auteri, MSC EMS PhD, UCB Pharma, Brussels, Belgium, for publication coordination and Jessica Patel, PhD, Costello Medical, UK, for medical writing and editorial assistance based on the authors' input and direction. This study was funded by UCB Pharma.

Contributors Substantial contributions to study conception and design: RL, DvdH, $M D, X B, F V d B, K G, O D, L B, B H$ and $L S G$; contributions to analysis and interpretation of the data: RL, DvdH, MD, XB, FVdB, KG, OD, NdP, LB, BH, KT and LSG; drafting the article or revising it critically for important intellectual content: RL, DvdH, MD, XB, $F V d B, K G, O D, N d P, L B, B H, K T$ and $L S G$; final approval of the version of the article to be published: RL, DvdH, MD, XB, FVdB, KG, OD, NdP, LB, BH, KT and LSG.

Funding This article was based on the original study AS0005/C-OPTIMISE (NCT02505542) sponsored by UCB Pharma. Support for third-party writing assistance for this article, provided by Jessica Patel, PhD, Costello Medical, UK, was funded by UCB Pharma in accordance with Good Publication Practice guidelines (http://www.ismpp.org/gpp3)

Competing interests RL: Consulting fees and/or research grants from AbbVie, Ablynx, Amgen, AstraZeneca, Bristol-Myers Squibb, Centocor, Galapagos, GlaxoSmithKline, Janssen, Eli Lilly, Merck, Novartis, Pfizer, Roche, Schering and UCB Pharma. DvDH: Consulting fees from AbbVie, Amgen, Astellas, AstraZeneca, Bristol-Myers Squibb, Boehringer Ingelheim, Celgene, Cyxone, Daiichi, Eli Lilly, Galapagos, Gilead, Janssen, Merck, Novartis, Pfizer, Regeneron, Roche, Sanofi, Takeda and UCB Pharma; director of Imaging Rheumatology BV. MD: Consultancy/ speaker fees/research grants from AbbVie, Eli Lilly, Novartis, Merck, Pfizer and UCB Pharma. XB: Consultancy/speaker fees/research grants from AbbVie, Bristol-Myers Squibb, Celgene, Chugai, Janssen, MSD, Novartis, Pfizer and UCB Pharma and grant/ research support from AbbVie, Bristol-Myers Squibb and Celgene. FVdB: Consultancy fees from AbbVie, Bristol Myers-Squibb, Celgene, Janssen, Merck, Novartis, Pfizer and UCB Pharma; speakers bureau fees from AbbVie, Bristol Myers-Squibb, Celgene, Janssen, Merck, Novartis, Pfizer and UCB Pharma. KG: Consulting fees, research grants and speaker fees from AbbVie, Celgene, MSD, Novartis, Pfizer and UCB Pharma. OD, NdP, LB, BH: Employees of UCB Pharma. KT: Independent statistician contracted to UCB Pharma. LSG: Grant/research support from AbbVie, Amgen, Novartis and UCB Pharma; consulting fees from Galapagos, Eli Lilly and Janssen.

Patient and public involvement Patients and/or the public were involved in the design, or conduct, or reporting or dissemination plans of this research. Refer to the Methods section for further details.

\section{Patient consent for publication Not required.}

Ethics approval The study was approved by institutional review boards and independent ethics committees at participating sites and was conducted in accordance with local regulations and the International Conference on Harmonisation Good Clinical Practice requirements, based on the Declaration of Helsinki.

Provenance and peer review Not commissioned; externally peer reviewed.

Data availability statement Underlying data from this manuscript may be requested by qualified researchers six months after product approval in the US and/or Europe, or global development is discontinued, and 18 months after trial 
completion. Investigators may request access to anonymized individual patient-level data and redacted trial documents which may include: analysis-ready datasets, study protocol, annotated case report form, statistical analysis plan, dataset specifications, and clinical study report. Prior to use of the data, proposals need to be approved by an independent review panel at www.Vivli.organd a signed data sharing agreement will need to be executed. All documents are available in English only, for a prespecified time, typically 12 months, on a password protected portal.

Open access This is an open access article distributed in accordance with the Creative Commons Attribution Non Commercial (CC BY-NC 4.0) license, which permits others to distribute, remix, adapt, build upon this work non-commercially, and license their derivative works on different terms, provided the original work is properly cited, appropriate credit is given, any changes made indicated, and the use is non-commercial. See: http://creativecommons.org/licenses/by-nc/4.0/.

\section{ORCID iD}

Désirée van der Heijde http://orcid.org/0000-0002-5781-158X

\section{REFERENCES}

1 Sieper J, Poddubnyy D. Axial spondyloarthritis. Lancet 2017:390:73-84

2 Smolen JS, Schöls M, Braun J, et al. Treating axial spondyloarthritis and peripheral spondyloarthritis, especially psoriatic arthritis, to target: 2017 update of recommendations by an international Task force. Ann Rheum Dis 2018;77:3-17.

3 van der Heijde D, Ramiro S, Landewé R, et al. 2016 update of the ASAS-EULAR management recommendations for axial spondyloarthritis. Ann Rheum Dis 2017;76:978-91.

4 Feldtkeller E, Khan MA, van der Heijde D, et al. Age at disease onset and diagnosis delay in HLA-B27 negative vs. positive patients with ankylosing spondylitis. Rheumatol Int 2003:23:61-6.

5 Boonen A, Sieper J, van der Heijde D, et al. The burden of non-radiographic axial spondyloarthritis. Semin Arthritis Rheum 2015;44:556-62.

6 Baraliakos X, Braun J. Non-Radiographic axial spondyloarthritis and ankylosing spondylitis: what are the similarities and differences? RMD Open 2015;1:e000053.

7 Westhovens R, Annemans L. Costs of drugs for treatment of rheumatic diseases. RMD Open 2016;2:e000259.

8 Emery P, Hammoudeh M, FitzGerald O, et al. Sustained remission with etanercept tapering in early rheumatoid arthritis. N Eng/ J Med 2014;371:1781-92.

9 Hindryckx P, Zou GY, Feagan BG, et al. Biologic drugs for induction and maintenance of remission in Crohn's disease: a network meta-analysis. Cochrane Database Syst Rev 2017:2017:CD012751.

10 Edwards CJ, Fautrel B, Schulze-Koops H, et al. Dosing down with biologic therapies: a systematic review and clinicians' perspective. Rheumatology(Oxford) 2017:56:1847-56

11 Landewé R, Sieper J, Mease P, et al. Efficacy and safety of continuing versus withdrawing adalimumab therapy in maintaining remission in patients with nonradiographic axial spondyloarthritis (ABILITY-3): a multicentre, randomised, doubleblind study. Lancet 2018;392:134-44.

12 Navarro-Compán V, Plasencia-Rodríguez C, de Miguel E, et al. Anti-Tnf discontinuation and tapering strategies in patients with axial spondyloarthritis: a systematic literature review. Rheumatology 2016;55:1188-94.
13 van der Heijde D, Dougados M, Landewé R, et al. Sustained efficacy, safety and patient-reported outcomes of certolizumab pegol in axial spondyloarthritis: 4-yea outcomes from RAPID-axSpA. Rheumatology 2017;56:1498-509.

14 Deodhar A, Gensler LS, Kay J, et al. A fifty-two-week, randomized, placebo-controlled trial of certolizumab pegol in nonradiographic axial spondyloarthritis. Arthritis Rheumatol 2019:71:1101-11.

15 Machado PM, Landewé R, van der Heijde D, et al. Ankylosing spondylitis disease activity score (ASDAS): 2018 update of the nomenclature for disease activity states. Ann Rheum Dis 2018;77:1539.

16 Machado P, Landewé $R$, Lie E, et al. Ankylosing spondylitis disease activity score (ASDAS): defining cut-off values for disease activity states and improvement scores. Ann Rheum Dis 2011;70:47-53.

17 Rudwaleit M, van der Heijde D, Landewé R, et al. The Assessment of SpondyloArthritis international Society classification criteria for peripheral spondyloarthritis and for spondyloarthritis in general. Ann Rheum Dis 2011;70:25-31.

18 van der Linden S, Valkenburg HA, Cats A. Evaluation of diagnostic criteria for ankylosing spondylitis. A proposal for modification of the New York criteria. Arthritis Rheum 1984;27:361-8.

19 Anderson JJ, Baron G, van der Heijde D, et al. Ankylosing spondylitis assessment group preliminary definition of short-term improvement in ankylosing spondylitis. Arthritis Rheum 2001:44:1876-86.

20 Brandt J, Listing J, Sieper J, et al. Development and preselection of criteria for short term improvement after anti-TNF alpha treatment in ankylosing spondylitis. Ann Rheum Dis 2004;63:1438-44.

21 Garrett S, Jenkinson T, Kennedy LG, et al. A new approach to defining disease status in ankylosing spondylitis: the Bath ankylosing spondylitis disease activity index. J Rheumatol 1994:21:2286-91.

22 Calin A, Garrett S, Whitelock H, et al. A new approach to defining functional ability in ankylosing spondylitis: the development of the Bath ankylosing spondylitis functional index. J Rheumatol 1994;21:2281-5.

23 Jenkinson TR, Mallorie PA, Whitelock HC, et al. Defining spinal mobility in ankylosing spondylitis (AS). The Bath AS Metrology index. J Rheumatol 1994;21:1694-8.

24 van der Heijde $D$, Landewé $R$, Feldtkeller E. Proposal of a linear definition of the Bath Ankylosing Spondylitis Metrology index (BASMI) and comparison with the 2-step and 10-step definitions. Ann Rheum Dis 2008:67:489-93.

25 Landewé RB, Hermann K-GA, van der Heijde D, et al. Scoring sacroiliac joints by magnetic resonance imaging. A multiple-reader reliability experiment. J Rheumatol 2005;32:2050-5.

26 Lukas C, Braun J, van der Heijde D, et al. Scoring inflammatory activity of the spine by magnetic resonance imaging in ankylosing spondylitis: a multireader experiment. J Rheumatol 2007:34:862-70.

27 Heuft-Dorenbosch L, Spoorenberg A, van Tubergen A, et al. Assessment of enthesitis in ankylosing spondylitis. Ann Rheum Dis 2003;62:127-32.

28 Gratacós J, Pontes C, Juanola X, et al. Non-inferiority of dose reduction versus standard dosing of TNF-inhibitors in axial spondyloarthritis. Arthritis Res Ther 2019;21:11.

29 Molto A, Gossec L, Meghnathi B, et al. An Assessment in SpondyloArthritis international Society (ASAS)-endorsed definition of clinically important worsening in axial spondyloarthritis based on ASDAS. Ann Rheum Dis 2018;77:124-7. 